\title{
Regime-Switching Stochastic Volatility and Short-term Interest Rates
}

\author{
Madhu Kalimipalli ${ }^{\text {a }}$ \\ School of Business and Economics \\ Wilfrid Laurier University \\ Waterloo, Ontario N2L 3C5, Canada \\ Tel: 519-884-0710 (Ext.: 2187) Fax: 360-234-1328 \\ mkalimip@wlu.ca

\section{Raul Susmel} \\ C.T. Bauer College of Business \\ University of Houston, \\ Houston, TX 77204-6282, USA \\ rsusmel@uh.edu
}

(This version June 2003)

\begin{abstract}
In this paper, we introduce regime-switching in a two-factor stochastic volatility (SV) model to explain the behavior of short-term interest rates. We model the volatility of short-term interest rates as a stochastic volatility process whose mean is subject to shifts in regime. We estimate the regime-switching stochastic volatility (RSV) model using a Gibbs Sampling-based Markov Chain Monte Carlo algorithm. In-sample results strongly favor the RSV model in comparison to the single-state SV model and GARCH family of models. Out-of-sample results are mixed and, overall, provide weak support for the RSV model.
\end{abstract}

Key Words: Short-term interest rates, stochastic volatility, regime switching, MCMC methods, GARCH models.

JEL Classification: G10, G12

\footnotetext{
a Corresponding Author. We acknowledge the comments of Arthur Warga and seminar participants at the University of Houston, McGill University and the NFA 2000 Meetings in Waterloo. We thank Siddhartha Chib for providing us with very helpful computational tips. We also thank the editor, associated editor and two anonymous referees for their valuable comments.
} 


\title{
Regime-Switching Stochastic Volatility and Short-term Interest Rates
}

\begin{abstract}
In this paper, we introduce regime-switching in a two-factor stochastic volatility (SV) model to explain the behavior of short-term interest rates. We model the volatility of short-term interest rates as a stochastic volatility process whose mean is subject to shifts in regime. We estimate the regime-switching stochastic volatility (RSV) model using a Gibbs Sampling-based Markov Chain Monte Carlo algorithm. In-sample results strongly favor the RSV model in comparison to the single-state SV model and GARCH family of models. Out-of-sample results are mixed and, overall, provide weak support for the RSV model.
\end{abstract}

Key Words: Short-term interest rates, stochastic volatility, regime switching, MCMC methods, GARCH models.

JEL Classification: G10, G12 


\section{Regime-Switching Stochastic Volatility and Short-term Interest Rates}

\section{Introduction}

The dynamics of short-term treasury interest rates are central to the pricing of all fixed income instruments and their derivatives. Chan, Karolyi, Longstaff and Sanders (1992) compare a variety of single factor continuous-time models of the short-term riskless rate. They find that models that allow the volatility of interest changes to be sensitive to the level of the risk-free rate outperform other models. Longstaff and Schwartz (1992) present a two-factor general equilibrium model, with the level and conditional volatility of short-term rates as factors. They show that a two-factor model carries additional information about the term structure and leads to better pricing and hedging performance compared to a single factor model, which only uses the level of the short rate.

Brenner, Harjes and Kroner (1996) show that interest rate models that include both a level effect (where the interest rate volatility is a function of its level) and a Generalized Autoregressive Conditional Heteroscedasticity (GARCH) specification outperform those models that exclude one of them. Koedijk, Nissen, Scotchman, and Wolff (1997) find that both level and GARCH effects are important determinants of interest rate volatility, and ignoring GARCH effects leads to an omitted variables problem for the estimation of the level effect. On the other hand, Anderson and Lund (1997) and Ball and Torous (1999) find that a two-factor interest rate model with level and stochastic volatility (SV) factors outperforms the GARCH volatility models. Durham (2001) reports that while two-factor models provide a large improvement in the likelihood compared to single factor models, they do not provide any improvement in bond-pricing performance. 
Previous studies have also documented strong evidence for regime switching in shortterm interest rates. For example, Gray (1996) presents evidence for i) a mean reverting highvolatility state with low volatility persistence and ii) a non-mean reverting low-volatility state with high volatility persistence in one-month U.S. T-Bill yields. Regime switching in the drift and volatility of the short rate has important implications for yield curve dynamics, immunization and hedging strategies. As Litterman, Scheinkman and Weiss (1991) and Brown and Schaefer (1995) point out, the volatility of the short-term interest rate affects the curvature of the yield curve. When regime switching in volatility is not considered, volatility shocks tend to be very persistent. This, in turn, could amplify the hump in the yield curve.

In this paper, we incorporate regime-switching in SV models and compare the performance relative to other popular two-factor models. In particular, we examine if the volatility shocks from regime-switching carry any additional information beyond what is already contained in the SV model. We model the volatility of short-term interest rates as a stochastic process whose mean is subject to shifts in regime. The motivation behind the regime-switching SV model is similar to the intuition behind the jump-diffusion SV processes. ${ }^{1}$ We employ a Gibbs Sampling-based Markov Chain Monte Carlo algorithm to estimate our model. We find that the usual high volatility persistence is substantially reduced by the introduction of regime-switching. In general, SV models outperform GARCH models both in-sample and out-of sample. In-sample, the regime-switching SV model performs better than the single-state SV model. Out-of-sample, the regime-switching SV model performs marginally better than the single-state SV model, especially when, as 
expected, the out-of-sample period experiences regime-switching. The out-of-sample results, however, do not provide overwhelming support for the regime-switching SV model.

The rest of the paper is structured as follows. Section 2 provides a brief background to regime-switching interest rate models. Section 3 describes the regime-switching SV model. Section 4 describes the data set used in this paper. Section 5 discusses the results from estimation. Section 6 presents the in-sample and out-of-sample comparative performance of the RSV model. Section 7 summarizes and presents our conclusions.

\section{Regime-Switching Models: Background and Literature}

A common empirical finding in two-factor models is a high persistence in the conditional variance. For example, Brenner et al. (1996) and Anderson and Lund (1997) estimate the persistence parameter, i.e., the sum of the autoregressive coefficients, in the conditional variance equation to be 0.82 and 0.98 , respectively, for the weekly three-month U.S. T-Bill yields. Ball and Torous (1999) report the persistence parameter to be 0.928 for the monthly one-month U.S. T-Bill yields.

High persistence in the conditional variance implies that shocks to the conditional variance do not die out quickly and that current information has a significant effect on the conditional variance for future horizons. Lamoreux and Lastrapes (1990) show that in the presence of any structural changes, the variance process may exhibit spuriously high persistence. Similar results were documented by Hamilton and Susmel (1994), Cai (1994) and So, Lam and Li (1998). Previous research finds strong evidence of regime-switching in U.S.

\footnotetext{
${ }^{1}$ For example, Eraker, Johannes and Polson (2003), Bates (2000), Duffie, Singleton and Pan (2000) and Pan (2001) show, in the context of stock returns, that jumps in volatility may remove possible misspecifications in
} 
short-term interest rates (see Hamilton (1988), Driffill (1992), Albert and Chib (1993) and Cai (1994)). Both Gray (1996) and Bekaert, Hodrick and Marshal (2001) find evidence of a high (low) volatility regime with high (low) mean reversion in short-term interest rates. Various macro-economic events (such as oil shocks, the monetary experiment of late 70's, the October 1987 crash and wars involving the U.S.) were responsible for regime-switching in U.S. interest rates. When short-term risk-free rates switch randomly between regimes, with different means and variances, one may find high persistence in the volatility when data is averaged across these regimes.

Gray (1996) reports that a generalized regime-switching interest rate model with state-dependent mean reversion and conditional heteroscedasticity effects outperforms GARCH-type models. Naik and Lee (1998) show that the regime-switching model generates an empirically more reasonable term structure of volatilities, fat tails, and persistence in volatility compared to the SV models. Ang and Bekaert (2002a) find that regime-switching models of interest rates replicate non-linear patterns in the drift and volatility functions of short rates found in non-parametric approaches. Ang and Bekaert (2002b) find that regime-switching models forecast better than one-regime models out-of sample. Bekaert, Hodrick and Marshal (2001) find that that the term-premium dynamics coupled with regime-switching effects, which proxy peso problems, lead to small-sample distributions more consistent with the data. Evans (2003) finds that the regime-switching model with three states has a good fit for the U.K. interest rates. Bansal and Zhou (2002) show that both the Cox, Ingersoll and Ross (1985) model and a three-factor affine model are 
sharply rejected in favor of the regime-switching model, where regime shifts affect the market price of risk.

In summary, earlier literature shows strong evidence for regime-switching in shortterm interest rates. In this paper, we focus on the rele vance of regime-switching for SV models. Our choice for a regime-switching process is motivated by the evidence for regime changes in interest data.

\section{Regime-switching Stochastic Volatility (RSV) model}

In this section, we describe an $\mathrm{SV}$ model that incorporates regime-switching. Consider the short-term interest rate process described below:

$$
\begin{aligned}
& r_{t}-r_{t-1}=a_{0}+a_{1} r_{t-1}+\sqrt{h_{t} r_{t-1}^{2 \alpha}} \varepsilon_{t}, \quad \alpha=0.5 \\
& \left(\ln \left(h_{t}\right)-\mu_{s_{t}}\right)=\phi_{1}\left(\ln \left(h_{t-1}\right)-\mu_{s_{t-1}}\right)+\sqrt{\sigma_{\eta}^{2}} \eta_{t-1} \\
& \mu_{s_{t}}=\beta+\gamma s_{t} \quad \gamma>0 \quad s_{t}=\{1,2, \ldots, \mathrm{k}\} \\
& \operatorname{prob}\left[s_{t}=j \mid s_{t-1}=i\right]=p_{i j}
\end{aligned}
$$

In model (1), $r_{t}$ is the short rate, $h_{t}$ is the conditional variance of the short rate, $\alpha$ captures the levels effect in the model, $\mu_{s_{t}}$ is the stationary mean of the natural $\log$ of $h_{t}, \phi_{1}$ measures the degree of persistence of $\ln \left(h_{t}\right), \varepsilon_{t}$ and $\eta_{t}$ represent shocks to the mean and volatility respectively, $\sigma_{\eta}^{2}$ is the variance of the volatility shock and $x_{t}$ is a vector of explanatory variables (in our model, $x_{t}$ is a vector of ones). Both shocks are white noise errors, which are assumed to be distributed independently of each other. The parameter $\gamma$ measures the sensitivity of the mean variable with respect to the underlying state and is constrained to be positive. The transition probability parameter $p_{i j}$, where $\mathrm{i}$ and $\mathrm{j}=\{0,1\}$, represents the transition probability of going from state $\mathrm{i}$ to $\mathrm{j}$. 
Note that $\mu$ is a function of the latent state $s_{t}$, which follows a k-state ergodic discrete first-order Markov process as in Hamilton (1988). The underlying state $s_{t}$ can assume k possible states, i.e., one of $\{1,2, \ldots . ., \mathrm{k}\}$, where higher values of $s_{t}$ lead to higher intercept terms in the log variance equation. As an identification condition, we require each regime to correspond to at least one time point. A k-state stationary transition probability matrix governs the dynamics of the transition from one state to the next state. We can also think of our latent volatility as a mixture of $\mathrm{k}$ densities, where each density corresponds to a single state. The latent volatility at a given time comes from a single density, which is decided by an underlying k-state Markov process. Following the existing switching literature, we limit ourselves to two states: a high volatility state and a low volatility state, i.e., we set $\mathrm{k}=2$.

Model (1) is referred to as a Regime-switching Stochastic Volatility (RSV) model. The RSV model specification combines a level effect and a conditional volatility process that is driven by two shocks, $s_{t}$ and $\eta_{t}$. The estimation of the RSV model involves estimation of mean parameters $\left\{a_{0}, a_{l}\right\}$, variance parameters $\left\{\alpha, \beta, \gamma, \sigma_{\eta}^{2}, \phi_{l}\right\}$, and transition probability parameters $\left\{p_{01}, p_{10}\right\}$. The RSV model reduces to the Single-state Stochastic Volatility (SSV) model when $\mu$ is state independent, that is, when $\gamma$ is equal to zero. The SSV model is a commonly used SV model; see, for example, Ball and Torous (1999) and Anderson and Lund (1997). The SSV model also reduces to the Brenner et al. (1996) model when the conditional volatility is specified as a GARCH process. In the RSV specification, the drift term of the conditional variance is a function of both current and previous period states, while in the So et al. (1998) model, the conditional variance is a function only of the current period state. 
The estimation of the RSV model involves estimating two latent variables, i.e., $h_{t}$ and $s_{t}$, in addition to the model parameters. In the presence of two latent variables, the likelihood function for the model needs to be integrated over all the possible states of the two latent variables. Jacquier, Polson and Rossi (1995) show that maximum likelihood-based methods tend to fail under complex specifications of the likelihood function. Consequently, we resort to Monte Carlo Markov Chain (MCMC) methods to estimate the RSV model. ${ }^{2}$ MCMC methods have been widely used in the estimation of unobserved component models. See for example, Jones (2003), Lamoreux and Witte (2002) and Eraker (2001).

In the RSV model (1), we need to estimate the parameter vector $\theta=\left\{\beta, \gamma, \sigma_{\eta}^{2}, \phi_{1}, p_{01}\right.$, $\left.p_{10}\right\}$ along with the two latent variables, $H_{t}=\left\{h_{1}, \ldots, h_{t}\right\}$ and $S_{t}=\left\{\mathrm{s}_{1}, \ldots, s_{t}\right\}$. The parameter set therefore consists of $\omega=\left\{H_{t}, S_{t}, \theta\right\}$ for all $t$. Bayes theorem is used to decompose the joint posterior density as follows:

$$
f\left(H_{n}, S_{n}, \theta\right) \propto f\left(Y_{n} \mid H_{n}\right) f\left(H_{n} \mid S_{n}, \theta\right) f\left(S_{n} \mid \theta\right) f(\theta)
$$

We draw the marginals $f\left(H_{t} \mid Y_{t}, S_{t}, \theta\right), f\left(S_{t} \mid Y_{t}, H_{t}, \theta\right)$ and $f\left(\theta \mid Y_{t}, H_{t} S_{t}\right)$ using the Gibbs sampling algorithm. We first draw the underlying volatility $f\left(H_{t} \mid Y_{t}, S_{t}, \theta\right)$ using the multi-move simulation sampler based on De Jong and Shephard (1995). Representing the conditional mean as a mixture of normal variates as in Kim, Shephard and Chib (1998), we then draw from the seven underlying normals. We next draw the underlying Markov-state $f\left(S_{t} \mid Y_{t}, H_{t}, \theta\right)$ as in Carter and Kohn (1994). Then, we cycle through the conditionals of parameter vector $\theta$ for the volatility equation following Albert and Chib (1993) and Chib (1993). For the Gibbs estimation, we set the burn-in iterations as 4,000. We sample from the next 6,000 draws and choose every fifth

\footnotetext{
${ }^{2}$ Details of the MCMC estimation and simulation experiments are in two Appendices, A and B, which are available upon request or on the web at www.bauer.uh.edu/ rsusmel/Academic/KSAppendix.pdf.
} 
observation to minimize possible correlation in the draws. We construct $95 \%$ confidence intervals and the standard errors for the parameters. We estimate the density functions for the parameters based on the Gaussian kernel estimator (Silverman (1986)).

\section{Data}

The data consist of annualized yields based on weekly observations of three-month U.S. T-bill data for the period 01/06/60 to 06/03/98 (2,003 weekly observations) and are obtained from the Chicago Federal Reserve's database. Wednesday's rates are used, and if Wednesday is a trading holiday, then Tuesday's rates are used. Similar three-month T-Bill yields have been previously used by Brenner et al. (1996) and Anderson and Lund (1997) to proxy the short rate. Using one-month or three-month maturity T-Bill yields as proxies for instantaneous short rates leads to biases when pricing short-tem maturity bonds. Chapman, Long and Pearson (1999) show that such biases are generally negligible.

Table 1 presents the summary statistics of the data. Changes in yields, $\Delta r_{t}$, seem to be left-skewed, indicating that yield increases were less common than yield decreases on a weekly basis. There is also strong evidence of kurtosis in the return series. The Ljung-Box statistic suggests that there is a high degree of autocorrelation for the raw yields $\left(r_{t}\right)$. On the other hand, $\Delta r_{t}$ series seems to be much less persistent and is characterized by low autocorrelations. The last row of Table 1 presents the Ljung-Box statistic for the squared residuals $\left(R E S_{t}^{2}\right)$ at various lags. The null of no ARCH effects is strongly rejected by the data. This indicates high autocorrelations in the data that imply time dependence in higher order moments. 


\section{Estimation of the Stochastic Volatility models}

Following Pagan and Schwert (1990) and Ball and Torous (1995, 1999), we fit the RSV model (1) to the residuals $\left(\mathrm{RES}_{\mathrm{t}}\right.$ ) from regressing $\Delta r_{t}$ on a constant and $r_{t-1}$. We set the level parameter $\alpha$ as $0.5 .^{3}$ For the purpose of estimation and comparison to alternative volatility models, we write our mean adjusted version of the RSV model as:

$$
\begin{aligned}
& \Delta r_{t}-\left(\hat{a}_{0}+\hat{a}_{1} r_{t-1}\right) \equiv R E S_{t} \\
& R E S_{t}=\sqrt{h_{t} r_{t-1}^{2 \alpha}} \varepsilon_{t}, \quad \alpha=0.5 \\
& \left(\ln \left(h_{t}\right)-\mu_{s_{t}}\right)=\phi_{1}\left(\ln \left(h_{t-1}\right)-\mu_{s_{t-1}}\right)+\sqrt{\sigma_{\eta}^{2}} \eta_{t-1} \\
& \mu_{s_{t}}=\beta+\gamma s_{t} \quad \gamma>0 \quad s_{t}=\{1,2\} \\
& \operatorname{prob}\left[s_{t}=j \mid s_{t-1}=i\right]=p_{i j}
\end{aligned}
$$

where all the assumptions on the error terms made in (1) still hold.

To benchmark our results, first, we ignore the possibility of regime-switching in the data. When we set $\gamma$ to zero, the RSV model (2) reduces to the SSV model. The results from

\footnotetext{
3 Anderson and Lund (1997), Brenner et al. (1996) and Ball and Torous (1995, 1999) find that $\alpha$ is not significantly different from 0.5 , providing evidence consistent with the Cox, Ingersoll and Ross (CIR) (1985) model. Gray (1996) sets $\alpha$ as 0.5 , arguing that "fixing $\alpha=0.5 \ldots$ facilitates interpretation in terms of CIR model." However, Chan et al. (1992) and Coonly et al. (1997) estimate a level parameter that is close to 1.5. Further, Bliss and Smith (1998) show that the Chan et al. (1992) finding that the level parameter is 1.5 is tied to their assumption that no structural break has occurred in their sample. They show that once regime switching is factored in, the $\alpha$ estimate drops to levels assumed by the CIR process. In our estimation, the level parameter is estimated as 0.67 , 0.68 and 0.46, respectively, in the SSV, RSV and EGARCH models (all estimates are not significantly different from 0.5 at the $1 \%$ level). The SV model estimates are close to those reported in Ball and Torous (1999). Moreover, we find that the comparative performance and the ordering of the models are unchanged (in Table 5) when $\alpha$ is estimated as a free parameter. Given these results, and the stated purpose of comparing alternative models in terms of their volatility forecasts, we set $\alpha=0.5$.
} 
the MCMC estimation of the SSV model are presented in Table 2, where the parameter set is $\theta$ $=\left\{\beta, \phi, \sigma_{\eta}^{2}\right\}$. The persistence parameter $\phi$ is very high, indicating that the half-life of a volatility shock, measured as $-\ln (2) / \ln (\phi)$, is about 14 weeks. Standard errors for the parameters are small, indicating that parameters are highly significant. Figure 1 plots the posterior densities of the parameters. All the parameters have symmetric densities, while half-life density is right-skewed (with mean and median of, respectively, 14.28 and 13.79). That is, we are more likely to observe half-lives less than the mean value of 14 weeks.

Next, we estimate the RSV model for our weekly interest data set. Table 3 presents the prior and posterior parameter estimates of the parameter set $\theta$ in our model, where $\theta=\{\beta, \gamma, \phi$, $\left.\sigma_{\eta}^{2}, p_{01,} p_{10}\right\}$. Standard errors for the parameters are small, as before. The persistence parameter, $\phi$, drops significantly to 0.628 from 0.951 in the SSV model. This implies that a switch in the latent regime creates a high persistence in volatility and confirms the earlier results in the literature. The distribution of $\phi$ is left-skewed with mean and median of 0.628 and 0.647 respectively (see Figure 2), implying that persistence greater than 0.628 is more common. The transition probabilities, $p_{00}$ and $p_{11}$, are estimated as 0.994 and 0.966 . These estimates are comparable to 0.9896 and 0.9739 , respectively, reported in Gray (1996) and 0.9878 and 0.9402, respectively, reported in Cai (1994). Our results imply that the effect of a volatility shock is much more persistent in the low volatility state than in the high volatility state. A volatility shock lasts about 100 weeks in the low volatility state compared to about 30 weeks in the high volatility state, where duration of the shock in state $i$ is obtained as $\left(1-p_{i i}\right)^{-1}$. Table 3 also shows that high volatility states tend to be associated with higher long-run mean of $\ln \left(h_{t}\right)$ compared to low volatility states. 
Figure 2 plots the densities for the posterior parameter estimates using a Gaussian kernel. The posterior densities seem to be right-skewed for $\sigma_{\eta}^{2}, p_{01}$ and $p_{10}$ (with medians 0.897 , 0.005 and 0.032 , respectively) and symmetric for $\beta$ and $\gamma$. The autocorrelation functions for parameters (not shown) become insignificant at very early lags. We also estimate the correlations between the parameters. Both SSV and RSV models have a strong negative correlation $\left(-0.551\right.$ and -0.776 respectively) between $\phi$ and $\sigma_{\eta}^{2}$, suggesting that there is a tradeoff between volatility persistence and volatility of volatility. The RSV model is also characterized by strong positive correlations between $\beta$ and $\gamma(0.606)$ and $\beta$ and $\sigma_{\eta}^{2}(0.501)$ and a negative correlation between $\beta$ and $\phi(-0.53)$. These findings suggest that high volatility periods are associated with high volatility regimes, high kurtosis and low persistence. The finding of low persistence in high volatility periods is consistent with Gray (1996).

The third and fourth panels in Figure 3 plot the latent annualized volatility and the smoother probabilities, respectively, of high- volatility states from the RSV model. Following Hamilton (1988), we consider an observation as belonging to state one if the smoothed probability is higher than 0.5 . The simulation smoother shows periods of high volatility during the oil shocks of 1969 and 1973, the 1979-83 Federal Reserve monetary experiment, and the market crash of 1987 . The smoother probabilities indicate that there is a large probability that the T-Bill yields during 1969, 1973, 1979-82, and 1987-88 belong to a high volatility regime. These high volatility dates are similar to the high volatility dates reported by Cai (1994) and Gray (1996). 


\section{Performance of the RSV Model}

\subsection{In-sample forecasts}

In this section, we conduct an extensive evaluation of the in-sample performance of the SV models in comparison to the GARCH family of models. We consider three popular GARCH models with normally distributed innovations: a GARCH(1,1) model, a GARCH(1,1)-L model (i.e., GARCH(1,1) with an asymmetry effect of negative lagged error, to capture the leverage effect) and an $\operatorname{EGARCH}(1,1)$ model. We also consider the Markov switching ARCH model, proposed by Hamilton and Susmel (1994), with two states and one autocorrelation lag or SWARCH(2,1) model. All the GARCH models are specified to include a level effect (for specifications see Table 4). The maximum likelihood estimation results for the three GARCH models are reported in Table 4. There is evidence for a leverage effect based on the significant t-statistic for $\kappa$ in the $\operatorname{GARCH}(1,1)-\mathrm{L}$ model and the significant t-statistic for $\delta_{2}$ in the EGARCH(1,1) model. The leverage effect, however, is small relative to the usual size found in equity returns. All the estimates in the conditional variance equation are significant for the three models. Note that the estimates show the previously documented high persistence in the conditional variance.

Next we present the in-sample metrics of the competing models for different in-sample periods. In addition to the full sample period, 01/06/60-06/03/98, we consider three sub-sample periods: (1) 01/06/60-12/31/78, (2) 01/06/60-12/31/82, and (3) 01/06/60-12/31/91. The first sample includes the oil shocks, the second sample includes the Fed Reserve experiment of 1979-82, and the third sample includes the October1987 stock market crash. We also include a fourth and a much shorter sample from 01/01/76-12/31/87; this sample has two well-defined spells of high volatility: the Fed experiment and the October 1987 stock market crash. 
Tables 5 and 6 present the results. We include a constant variance model as a benchmark for conditional volatility models. In general, the SV models have higher loglikelihood values, adjusted $\mathrm{R}^{2} \mathrm{~s}$ and $\mathrm{AIC} / \mathrm{SBC}$ values compared to the competing $\mathrm{ARCH}$ models. Within the SV models, RSV fares better than SSV based on these metrics. The posterior odds ratio captures the relative performance of each model with respect to the constant variance model (see Kim and Kon (1994)). If the odds ratio for a model is positive, then that model is "more likely" to have generated the data than the constant variance model. The model with the highest value of posterior odds ratio represents the "most likely" model specification. The stochastic volatility models, in general, have higher odds ratios than the ARCH models. Within SV models, the RSV performs better. In particular, the RSV model has an odds ratio that is at least $56 \%$ higher than the other competing models.

Table 5, in Panel A, also presents the mean squared error (MSE), the logarithmic loss function (LL) of Diebold and Lopez $(1996)^{4}$, and the Jarque-Bera normality test statistic (JB) for alternative models. The RSV model has the lowest MSE and LL values, closely followed by the SSV model. The JB statistic rejects the normality assumption for all the models except the RSV model. Among the GARCH models, with the exception of the Adjusted $\mathrm{R}^{2}$ criteria, the E-GARCH $(1,1)$ performs better than the other models for all the evaluation measures. Note also that the E-GARCH(1,1,) has an overall better performance than the SWARCH(2,1) model. The E-GARCH(1,1) is also the model used by Ball and Torous (1999) to evaluate the in-

\footnotetext{
${ }^{4}$ Although the MSE metric is used widely to compare alternative volatility models, its limitation lies in the fact that it penalizes positive volatility forecasts and negative volatility forecasts symmetrically (Bollerslev, Engle and Nelson (1994)). Diebold and Lopez (1996) discuss an alternative loss function called the logarithmic loss (LL) function, which penalizes volatility forecasts asymmetrically.
} 
sample evaluation of the SSV model. Based on these considerations, we select the EGARCH(1,1) model for subsequent out-of-sample tests of the SV models in Section 6.2.

We now turn to comparing the conditional volatilities implied by the models. The RSV model generates conditional volatilities within a tighter range compared to other models. The RSV model also seems to be sensitive to shocks or extreme observations; for example, the RSV model picks up an outlier in late 1982, which goes undetected by the other models. When we plot the conditional volatilities from the different models, in all high volatility regimes, i.e., during 1969, 1973, 1979-82, and 1987-88, the ARCH models tend to overestimate the conditional volatility relative to the SV models. There is a close correspondence between the RSV and SSV conditional volatilities. The RSV model seems to be more sensitive to shocks compared to the SSV. We also compare the two switching models, the RSV and SWARCH models. Figure 4 plots the conditional variance in the first panel and the high volatility state as estimated by the SWARCH$(2,1)$ model in the second panel. The SWARCH model tends to have lower volatility estimates compared to the RSV model. This is because the SWARCH model picks up high volatility states in 1968 and during 1991-93. These periods are in fact low volatility regimes according to the RSV model. (See the last panel of Figure 3 and the last panel of Figure 4.) Thus, in the second state the SWARCH model seems to be picking up the effects of some outliers that can be better described with a third state (see Hamilton and Susmel (1994) and Evans (2001)). The combination of regime switching and stochastic volatility provides a description of volatility states, which is consistent with the results in the interest rate literature (see Gray (1996)).

We next proceed to consider differences between conditional volatilities based on their statistical significance. We follow Diebold and Mariano (1995) who propose two non- 
parametric tests to test the null hypothesis of the equality of forecasts from two competing models: the sign test and the Wilcoxon signed rank test. ${ }^{5}$ The signed test is calculated as follows:

$$
\begin{aligned}
& S_{1 a}=\frac{S_{1}-.5 T}{\sqrt{.25 T}} \stackrel{a}{\sim} N(0,1) \\
& \text { where } S_{1}=\sum_{t=1}^{T} I\left(d_{t}\right) \text { and } I\left(d_{t}\right)=\left\{\begin{array}{c}
1 \text { if } d_{t}>0 \\
0 \text { otherwise }
\end{array}\right.
\end{aligned}
$$

where $d_{t}$ is the loss differential, defined as the difference between the forecast errors generated by the two competing models. The Wilcoxon signed rank test is calculated as follows:

$$
\begin{aligned}
& S_{2 a}=\frac{S_{2}-.25 T(T+1)}{\sqrt{\frac{T(T+1)(2 T+1)}{24}}} \sim N(0,1) \\
& \text { where } S_{2}=\sum_{t=1}^{T} I\left(d_{t}\right) \operatorname{Rank}\left(\left|d_{t}\right|\right) \text { and } I\left(d_{t}\right)=\left\{\begin{array}{c}
1 \text { if } d_{t}>0 \\
0 \text { otherwise }
\end{array}\right.
\end{aligned}
$$

Panel B in Table 5 presents results for the standard normal z statistic for the two tests. We find that the RSV model forecasts are significantly different from the forecasts of the competing models for the in-sample period. Note that the negative sign of the test statistic implies that the in-sample volatility forecasts from the RSV model are much lower than those from the constant volatility and other GARCH models. On the other hand, we find that the SSV model has lower in-sample volatility forecasts compared to the RSV model.

\footnotetext{
${ }^{5}$ Both tests are based on the null hypothesis that the median loss differential, defined as the difference between the forecast errors generated by the two competing models, is zero. While the signed test does not require distributional symmetry in the loss differential, the Wilcoxon signed rank test is based on the symmetry of loss differential functions. Both tests are based on the intuition that if the loss differential series is i.i.d., the number of positive loss-differential observations in a sample has a binomial distribution under the null. As the sample size increases, the two test statistics converge to standard normal distributions.
} 
Next we compare the RSV model with ARCH models based on the Vuong (1989) modified likelihood ratio test for comparing non-nested hypotheses. ${ }^{6}$ In the last column of Panel B we present Voung's statistics for the different models. In general, we find that the RSV model performs significantly different from the constant volatility model and the ARCH models at the $5 \%$ level.

Finally, the first half of Table 6 presents in-sample results for different sub-periods for the four models that are used for out-of-sample tests. Consistent with the in-sample results of Table 5, the RSV model once again outperforms competing models based on MSE, LL and mean absolute error (MAE) metrics. In-sample, the E-GARCH(1,1) model performs marginally better than the SSV model in sub-samples 2 and 3, which is consistent with the findings of Ball and Torous (1999).

Overall, our in-sample results are very supportive of the RSV model. However, given the richer parameterization of the RSV model relative to the other models, overfitting might play a part in the in-sample success of the RSV model. Thus, to better judge our RSV model, in the next section, we do an extensive out-of-sample evaluation of all the models.

\subsection{Out-of-sample forecasts}

Table 6 also reports the out-of-sample performance of the four models. We consider the constant volatility model, the best performing ARCH model based on the in-sample period, i.e., the E-GARCH $(1,1)$ and both SV models. We keep a constant volatility model in our out-

\footnotetext{
${ }^{6}$ The Vuong statistic is a likelihood ratio statistic adjusted by the standard deviation of the difference in maximum log-likelihood functions under the competing models. Under the null hypothesis that the competing models are statistically indistinguishable, the Vuong statistic follows a standard normal distribution (see Ball and Torous (1999)).
} 
of-sample comparison, given the results in Figlewski (1997), where the constant volatility performs well relative to GARCH models.

We use the estimated coefficients from the in-sample period to generate one-week (step) ahead conditional volatility estimates for the out-of-sample period. Using estimates for the in-sample period 1 to $t$, we generate one-step-ahead conditional volatility forecasts for each future time period $t+\mathrm{k}$, where $\{\mathrm{k}=1,2,3, \ldots, \mathrm{T}-t ; \mathrm{T}$ is the sample size $\}$, based on the forecasting equations described in Table 6. We report MSE and MAE metrics for four different sub-samples in Table 6, under the column titled "fixed sample." Out-of-sample, the RSV model tends to do better than $\operatorname{EGARCH}(1,1)$ in most cases (only in sub-sample 3, are the MSEs the same for both models). In fact, the E-GARCH model never performs better than the SV models out-of-sample in terms of MAE. The RSV model also outperforms the SSV model in sub-sample 1 in terms of MSE and in sub-samples 1 and 2 in terms of MAE. For sub-sample 3, however, the out-of-sample performance of the RSV model and the SSV model are both similar. The results are not surprising because the less switching in the out-of-sample period, the less efficient the RSV model should be relative to the SSV model. Note that the out-ofsample period for sub-sample 1 includes both the 1979-82 and the 1987-88 high volatility regimes, whereas sub-sample 2 has the only 1987-87 regime, and sub-sample 3 has no highvolatility regimes. That is, the RSV model performs better than the SSV model whenever the out-of-sample period has regimes switching between low and high volatility. Consistent with Figlewski (1997), the constant variance model shows a good out-of-sample performance, especially in the MSE metric. Note that the constant variance model in the first sub-sample 
beats all the other models. The last sub-sample presents out-of-sample forecasts for a one year period. Again, the RSV model shows superior performance. ${ }^{7}$

In Table 6, we present more out-of-sample results under the column titled "increasing sample," using a different forecasting methodology. We forecast the one-step ahead conditional volatility using all the competing models. We obtain the successive forecasts by increasing the sample size; i.e., for time period t, the sample size includes observations 1 to $t$, for next time period $t+1$, the sample size includes observations 1 to $t+1$, and so on. We estimate the model each time and generate a forecast for the next period. We present the LL and MAE metrics for four sub-sample periods. The RSV model has the lowest error based on the LL metric. Based on the MAE, the SSV performs as well as the RSV model in sub-samples 1 and 3 and better than the RSV model in sub-samples 2 and 4 . We also calculate a sign test and a Wilcoxon signed rank test to compare the RSV model forecasts with others for all the sub periods. Although not reported, we find that the RSV model forecasts are significantly lower compared to other models.

In summary, the in-sample results show that the SV models are superior to the ARCHtype models based on different metrics. Within the ARCH models, the EGARCH $(1,1)$ has the best in-sample performance. The SV models have significantly lower conditional volatility estimates compared to the ARCH models. Within the SV models, the RSV performs better than the SSV model. This in-sample performance of the RSV model is also robust to different sub-samples. The out-of-sample results show that the SV models generally outperform the best performing ARCH model, the E-GARCH(1,1) model. We notice that the RSV model does

\footnotetext{
${ }^{7}$ For the fourth sample, we also calculate (not reported) out-of-sample forecasts for a two-year period and a 10year period. Overall, the results are similar, although as the out-of-sample forecasting period is extended, the
} 
better than the SSV model whenever regime-switching occurs in the out-of-sample period. However, there is no overwhelming support for the RSV model in the out-of-sample forecasting experiment.

\section{Summary and Conclusions}

In this paper, we introduce regime-switching in a two-factor stochastic volatility model to explain the behavior of short-term interest rates. That is, we model the volatility of shortterm interest rates as a stochastic volatility process whose mean is subject to shifts in regime. We find that the usual high volatility persistence is substantially reduced by the introduction of regime-switching. We find that stochastic volatility models outperform the ARCH models both in-sample and out-of-sample. The in-sample results show that the RSV model outperforms the single-state SV model. The out-of-sample results, however, are not that clear. The out-of-sample results tend to marginally favor the RSV model, especially whenever that period experiences regime-switching. Given that the out-of-sample results are not overwhelming in favor of the RSV model, we also evaluate the RSV and SSV models by studying their option pricing implications. We find that the RSV model generates significantly different prices compared to the single-state SV model In particular, the RSV model is associated with lower option prices in highly volatile periods. Our results are consistent with those of Vetzal (1997), who finds that the stochastic volatility models typically generate lower historical volatilities and hence lower option prices than constant volatility and GARCH models.

performance of the SSV model becomes very similar to the performance of the RSV model. 


\section{References:}

Albert, J. H., Chib, S., 1993. Bayes inference via Gibbs sampling of autoregressive time series subject to regime shifts. Journal of Business Statistics and Economics 11, 1-15.

Anderson, T., Lund, J., 1997. Estimating continuous time stochastic volatility models of the short-term interest rates. Journal of Econometrics 77, 343-77.

Ang, A., Bekaert, G., 2002a. Short rate non-linearities and regime switches. Journal of Economic Dynamics and Control 26, 1243-1274.

Ang, A., Bekaert, G., 2002b. Regime switches in interest rates. Journal of Business and Economic Statistics 20, 163-182.

Ball, C., Torous, W. N., 1995. Regime shifts in short term riskless interest rates. Working Paper \#15-95, Anderson School of Management, University of California at Los Angeles.

Ball, C., Torous, W. N., 1999. The stochastic volatility of short-term interest rates: some international evidence. Journal of Finance 56, 2339-2359.

Bansal, R., Zhou, H., 2002. Term structure of interest rates with regime shifts. Journal of Finance 57, 1997-2043.

Bates, D. S., 2000. Post-' 87 crash fears in the S\&P 500 Futures option market. Journal of Econometrics 94, 181-238.

Bekaert, G., Hodrick, R. J., Marshall, D.A., 2001. Peso problem explanations for term structure anomalies. Journal of Monetary Economics 48, 241-270.

Bliss, R. R., Smith, D.C., 1998. The elasticity of interest rate volatility: Chan, Karolyi, Longstaff, and Sanders Revisited. Journal of Risk 1, 1, 21-46.

Bollerslev, T., Engle, R. F., Nelson, D., 1994. ARCH models, in: Engle, R. F., McFadden, D., Handbook of Econometrics, Vol. 4. Elsevier, Amsterdam.

Brenner, R. J., Harjes, R., Kroner, K., 1996. Another look at models of short-term interest rates. Journal of Financial and Quantitative Analysis 31, 85-107.

Brown, R. H., Schaeffer, S. M., 1995. Interest rate volatility and the shape of the term structure, in: Howison, S. D., Kelly, F. P., Wilmott, P., Mathematical Models in Finance, Chapman and Hall, London.

Cai, J., 1994. A Markov model of switching-regime ARCH. Journal of Business and Economic Statistics 12, 309-316. 
Carter, C. K., Kohn R., 1994. On Gibbs sampling for state space models. Biometrika 81, 54153.

Chan, K. C., Karolyi, G. A., Longstaff, F. A., Sanders, A., 1992. An empirical comparison of alternative models of the short-term interest rate. Journal of Finance 52, 1209-1227.

Chapman, D., Long, J.B., Pearson, D., 1999. Using the proxies for short rate: When are the three months like an instant? Review of Financial Studies 12, 4, 763-806.

Chib, S., 1993. Bayes estimation of regressions with autoregressive errors: a Gibbs sampling approach. Journal of Econometrics 58, 275-294.

Conley, T. G., Hansen, L. P., Luttmer, E.G. J., Scheinkman, J. A., 1997. Short-term interest rates as subordinated diffusions. Review of Financial Studies 10, 525-577.

Cox, J. C., Ingersoll, J. E., Ross, S. A., 1985. Theory of term structure of interest rates. Econometrica 53, 2, 385-407.

De Jong, P., Shephard, N., 1995. Simulation smoother for time series models. Biometrika 82, 339-50.

Diebold, F. X., Mariano, R., 1995. Comparing predictive accuracy. Journal of Business and Economic Statistics 13, 253-265.

Diebold, F. X., Lopez, J. A., 1996. Forecast evaluation and combination, in: Maddala, G. S., Rao, C. R., Statistical Methods in Finance, Elsevier, Amsterdam, 241-296.

Driffill, J., 1992. Changes in regime and term structure. Journal of Economic Dynamics and Control 16, 165-173.

Duffie, D., Singleton, K., Pan, J., 2000. Transform analysis and asset pricing for affine jumpdiffusions. Econometrica 68, 1343-1376.

Durham, G. B., 2001. Likelihood-based specification analysis of continuous models of the short term interest rate. Working Paper, University of Iowa.

Evans, D. D. M., 2003. Real risk, inflation risk and term structure. The Economic Journal 113, 487.

Eraker, B., 2001. MCMC analysis of diffusion models with applications to finance. Journal of Business and Economic Statistics 19, 2, 177-191.

Eraker, B., Johannes, M., Polson, N., 2003. The impact of jumps in volatility and returns. Journal of Finance 58, 3, 1269-1300. 
Figlewski, S., 1997. Forecasting volatility. Financial Markets, Institutions and Instruments 6, 1, New York University Salomon Center.

Gray, S., 1996. Modeling the conditional distribution of interest rates as a regime switching process. Journal of Financial Economics 42, 27-62.

Koedijk, K. G., Nissen, F. G. J. A., Scotchman, P. C., Wolff, C. C. P., 1997. The dynamics of short-term interest rate volatility reconsidered. European Finance Review 1, 105-130.

Hamilton, J. D., 1988. Rational expectations econometric analysis of changes in regime. Journal of Economic Dynamics and Control 12, 385-423.

Hamilton, J. D., Susmel, R., 1994. Autoregressive conditional heteroscedasticity and changes in Regime. Journal of Econometrics 64, 307-333.

Jacquier, E., Polson, N. G., Rossi, P. E., 1995. Bayesian analysis of stochastic volatility models. Journal of Business and Economic Statistics 12, 371-392.

Jones, C., 2003. The dynamics of stochastic volatility. Journal of Econometrics, forthcoming.

Kim. D., Kon, S. J., 1994. Alternative models for the conditional heteroscedasticity of stock returns. Journal of Business 67, 563-98.

Kim, S., Shephard, N., Chib, S., 1998. Stochastic volatility: likelihood inference and comparison with ARCH models. Review of Economic Studies 65, 361-94.

Lamoureux, C., Lastrapes, B., 1990. Persistence in variance, structural change, and the GARCH model. Journal of Business and Economic Statistics 8, 225-234.

Lamoureux, C., Witte, H. D., 2002. Empirical analysis of the yield curve: the information in the data viewed through the window of CIR. Journal of Finance 57, 3, $1479-1520$.

Litterman, R., Scheinkman, J. A., Weiss, J., 1991. Volatility and yield curve, Journal of Fixed Income, June, 49-53.

Longstaff, F. A., Schwartz, E., 1992. Interest rate volatility and term structure: A two-factor general equilibrium model. Journal of Finance 4, 1259-1282.

Naik,V., Lee, M. H., 1998. Yield curve dynamics with discrete shifts in economic regimes: theory and estimation. Working paper, Faculty of Commerce, University of British Columbia.

Pagan, A. R., Schwert, G. W., 1990. Alternative models for conditional stock volatility. Journal of Econometrics 45, 267-290. 
Pan, J., 2001. The jump risk premia implicit in options: evidence from integrated time series study. Journal of Financial Economics 63, 3-50.

So, M., Lam, K., Li, W., 1998. A stochastic volatility model with Markov switching. Journal of Business and Economic Statistics 16, 244-53.

Silverman, B. W., 1986. Density estimation for statistics and data analysis. Chapman and Hall, New York.

Vetzal, K. R., 1997. Stochastic volatility, movements in short term interest rates and bond option values. Journal of Banking and Finance 21,169-96.

Vuong, Q., 1989. Likelihood ratio tests for model selection and non-nested hypothesis. Econometrica 57, 307-33. 
Table 1. Univariate Statistics

\begin{tabular}{ccccc}
\hline & $\mathrm{r}_{\mathrm{t}}$ & $\Delta \mathrm{r}_{\tau}$ & $\left(\Delta \mathrm{r}_{\mathrm{t}}\right)^{2}$ & $\log \left(\Delta \mathrm{r}_{\mathrm{t}}\right)^{2}$ \\
\hline Mean & 6.044 & 0.000 & 0.049 & -5.672 \\
(standard error) & 0.060 & 0.005 & 0.004 & 0.057 \\
Variance & 7.259 & 0.049 & 0.040 & 6.530 \\
(standard error) & 0.319 & 0.004 & 0.008 & 0.203 \\
Skewness & 1.250 & -1.038 & 8.352 & -0.256 \\
(standard error) & 2.070 & 0.006 & 0.019 & 0.712 \\
Kurtosis & 4.878 & 17.658 & 88.586 & 2.941 \\
(standard error) & 22.157 & 0.009 & 0.049 & 6.658 \\
Ljung-Box (24) & 1733.4 & 12.018 & 100.96 & 190.78 \\
\hline LB-ARCH(24) & $\cdot$ & 104.47 & $\cdot$ &. \\
\hline
\end{tabular}

LB: Ljung-Box statistic is calculated with 24 lags. The $\chi_{(24)}^{2}$ critical value for a $95 \%$ confidence level is 36.4 .

LB-ARCH: Ljung-Box statistic is reported for the squared residuals at lag 24, where residuals are obtained from regressing $\Delta r_{t}$ on a constant and $r_{t-1}$. 
Table 2. Estimation of the SSV Model

\begin{tabular}{ccccccc}
\hline Parameters & \multicolumn{2}{c}{ Prior Values } & & \multicolumn{3}{c}{ Posterior Values } \\
\cline { 2 - 3 } \cline { 5 - 7 } & mean & $\begin{array}{c}\text { standard } \\
\text { deviation }\end{array}$ & & $\begin{array}{c}\text { mean (std. } \\
\text { error) }\end{array}$ & standard deviation & $\begin{array}{c}95 \% \\
\text { confidence } \\
\text { interval }\end{array}$ \\
\hline$\beta$ & 0.05 & 1 & & $2.831(0.020)$ & 0.219 & $(2.366-3.235)$ \\
$\phi$ & 0 & 10 & & $0.951(0.000)$ & 0.009 & $(0.932-0.969)$ \\
$\sigma^{2}$ & - & - & & $0.190(0.002)$ & 0.023 & $(0.150-0.241)$ \\
\hline
\end{tabular}

The Single-state Stochastic Volatility (SSV) model estimated above is:

$$
\begin{aligned}
& \Delta r_{t}-\left(\hat{a}_{0}+\hat{a}_{1} r_{t-1}\right) \equiv R E S_{t} \\
& R E S_{t}=\sqrt{h_{t} r_{t-1}^{2 \alpha}} \varepsilon_{t}, \quad \alpha=0.5 \\
& \left(\ln \left(h_{t}\right)-\mu\right)=\phi_{1}\left(\ln \left(h_{t-1}\right)-\mu\right)+\sqrt{\sigma_{\eta}^{2}} \eta_{t-1} \\
& \mu=\beta
\end{aligned}
$$

The sample size is 2,003. Prior distribution of $\sigma^{2}$ (inverse gamma) is improper. Details about the model estimation are in Section 3. The mean and median of half-life are, respectively, 14.28 and 13.79 weeks. 


\section{Table 3. Estimation of the RSV Model}

\begin{tabular}{ccccccc}
\hline Parameters & \multicolumn{2}{c}{ Prior Values } & & \multicolumn{3}{c}{ Posterior Values } \\
\cline { 2 - 3 } \cline { 5 - 6 } & mean & $\begin{array}{c}\text { standard } \\
\text { deviation }\end{array}$ & & $\begin{array}{c}\text { mean }(\text { std. } \\
\text { error })\end{array}$ & $\begin{array}{c}\text { standard } \\
\text { deviation }\end{array}$ & $\begin{array}{c}\text { 95\% confidence } \\
\text { interval }\end{array}$ \\
\hline$\beta$ & 0 & 50 & & $2.580(0.001)$ & 0.098 & $(2.378-2.769)$ \\
$\gamma$ & 1 & 50 & & $2.746(0.022)$ & 0.247 & $(2.258-3.220)$ \\
$\phi$ & 0 & 1 & & $0.628(0.001)$ & 0.046 & $(0.526-0.708)$ \\
$\sigma^{2}$ & - & - & & $0.931(0.002)$ & 0.123 & $(0.726-1.207)$ \\
$\mathrm{p}_{01}$ & 0.2 & 0.16 & & $0.006(0.001)$ & 0.003 & $(0.002-0.013)$ \\
$\mathrm{p}_{10}$ & 0.2 & 0.16 & & $0.034(0.001)$ & 0.013 & $(0.014-0.063)$ \\
\hline
\end{tabular}

The Regime-switching Stochastic Volatility (RSV) model estimated above is:

$$
\begin{aligned}
& \Delta r_{t}-\left(\hat{a}_{0}+\hat{a}_{1} r_{t-1}\right) \equiv R E S_{t} \\
& R E S_{t}=\sqrt{h_{t} r_{t-1}^{2 \alpha}} \varepsilon_{t}, \quad \alpha=0.5 \\
& \left(\ln \left(h_{t}\right)-\mu_{s_{t}}\right)=\phi_{1}\left(\ln \left(h_{t-1}\right)-\mu_{s_{t-1}}\right)+\sqrt{\sigma_{\eta}^{2}} \eta_{t-1} \\
& \mu_{s_{t}}=\beta+\gamma s_{t} \quad \gamma>0 \quad s_{t}=\{1,2\} \\
& \operatorname{prob}\left[s_{t}=j \mid s_{t-1}=i\right]=p_{i j}
\end{aligned}
$$

The sample size is 2,003. Prior distribution of $\sigma^{2}$ (inverse gamma) is improper. Details about the modelestimation are in Section 3. 


\section{Table 4. Estimation of ARCH Models}

Results from the maximum likelihood estimation of GARCH models using weekly 3-month T-Bill rates for the period 01/06/60 to 06/03/98

\begin{tabular}{cccccccc}
\hline & $\alpha_{0}$ & $\kappa$ & $\gamma$ & $\delta_{1}$ & $\delta_{2}$ & $\alpha_{1}$ & $\beta_{1}$ \\
\hline GARCH(1,1) & 0.776 & - & - & - & - & 0.023 & 0.851 \\
& $(-5.11)$ & & & & & $(-7.164)$ & $(-47.012)$ \\
GARCH(1,1)-L & 0.787 & 0.009 & - & - & - & 0.019 & 0.847 \\
& $(-5.15)$ & $(-2.566)$ & & & & $(-6.501)$ & $(-46.993)$ \\
E-GARCH(1,1) & 0.054 & - & - & 0.144 & -0.019 & - & 0.944 \\
& $(-2.802)$ & & & $(-11.567)$ & $(-3.434)$ & - & $(-128.91)$ \\
SWARCH(2,1) & 12.436 & - & 10.394 & & & 0.031 & \\
& $(-14.483)$ & & $(-10.528)$ & & & $(-5.121)$ & \\
\hline
\end{tabular}

t-statistics are reported in parenthesis. The general model used is:

$$
\begin{aligned}
& \Delta r_{t}-\left(\hat{a}_{0}+\hat{a}_{1} r_{t-1}\right) \equiv R E S_{t} \\
& R E S_{t}=u_{t}=\sqrt{h_{t} r_{t-1}^{2 \alpha}} \varepsilon_{t}, \quad \alpha=0.5 \quad\left(\varepsilon_{t} \mid \Omega_{t-1}\right) \sim N(0,1)
\end{aligned}
$$

The conditional volatility, $h_{t}$, has four alternative specifications:

$\underline{\operatorname{GARCH}(1,1):}$

$$
\begin{aligned}
& h_{t}=\alpha_{0}+\alpha_{1} u_{t-1}^{2}+\beta_{1} h_{t-1} \quad t>1 \\
& h_{1}=\frac{\alpha_{0}}{1-\alpha_{1}-\beta_{1}} \quad t=1
\end{aligned}
$$

$\underline{\operatorname{GARCH}(1,1)-\mathrm{L}:}$

$$
\begin{aligned}
& h_{t}=\alpha_{0}+\kappa d_{t-1} u_{t-1}^{2}+\alpha_{1} u_{t-1}^{2}+\beta_{1} h_{t-1} \quad t>1 \\
& d_{t-1}= \begin{cases}0 \text { if } u_{t-1}>0 \\
1 \text { if } u_{t-1} \leq 0\end{cases} \\
& h_{1}=\frac{\alpha_{0}}{1-\frac{\kappa}{2}-\alpha_{1}-\beta_{1}} \quad t=1
\end{aligned}
$$

$\underline{\operatorname{EGARCH}(1,1):}$

$$
\begin{aligned}
& \ln \left(h_{t}\right)=\alpha_{0}+\delta_{1}\left(\left|\varepsilon_{t-1}\right|-\sqrt{\frac{2}{\pi}}\right)+\delta_{2} \varepsilon_{t-1}+\beta_{1} \ln \left(h_{t-1}\right) \quad t>1 \\
& \ln \left(h_{1}\right)=\frac{\alpha_{0}}{1-\beta_{1}} \quad t=1
\end{aligned}
$$

$\underline{\operatorname{SWARCH}(2,1):}$

$$
\begin{aligned}
& h_{t} / \gamma\left(s_{t}\right)=\alpha_{0}+\alpha_{1} u_{t-1}^{2} / \gamma\left(s_{t-1}\right) \quad t>1, \text { where } s_{t}=1,2 . \\
& \gamma\left(s_{t}\right) \text { is the multiplicative factorin each state. } \\
& \gamma\left(s_{t}=1\right)=1 \\
& \operatorname{Prob}\left[s_{t}=j \mid s_{t-1}=i\right]=p_{i j}
\end{aligned}
$$




\section{Table 5. In-sample Performance}

In-sample comparison of alternative models for the entire sample period $01 / 06 / 60$ to 06/03/98 (sample size: 2003)

\begin{tabular}{|c|c|c|c|c|c|c|c|c|c|}
\hline \multicolumn{10}{|l|}{ Panel A } \\
\hline & Pars. & $\begin{array}{c}\text { Log- } \\
\text { Likelihood }\end{array}$ & AIC & SBC & $\operatorname{Adj~} R^{2}$ & $\begin{array}{c}\text { Posterior } \\
\text { Odds } \\
\text { ratio }\end{array}$ & $\overline{M S E}$ & $\mathrm{LL}$ & JB \\
\hline Const. Variance & 1 & -8589.23 & -8590.23 & -8593.03 & -0.477 & - & 1.2 & 28.25 & $17453.05^{*}$ \\
\hline $\operatorname{GARCH}(1,1)$ & 3 & -7965.81 & -7968.81 & -7977.22 & 0.222 & 615.81 & 0.9 & 21.19 & $641.28 *$ \\
\hline $\operatorname{GARCH}(1,1)-\mathrm{L}$ & 4 & -7962.05 & -7966.05 & -7977.25 & 0.205 & 615.78 & 1.02 & 21.18 & $614.93^{*}$ \\
\hline $\operatorname{EGARCH}(1,1)$ & 4 & -7953.13 & -7957.13 & -7968.34 & 0.220 & 624.69 & 0.50 & 20.94 & $925.00^{*}$ \\
\hline $\operatorname{SWARCH}(2,1)$ & 5 & -7960.76 & -7965.76 & -7979.76 & 0.222 & 613.27 & 1.01 & 21.01 & $14.30 *$ \\
\hline SSV model & 3 & -7883.92 & -7886.92 & -7895.33 & 0.448 & 697.70 & 0.21 & 17.35 & $230.19^{*}$ \\
\hline RSV model & 6 & -7397.39 & -7401.39 & -7412.6 & 0.602 & 1180.43 & 0.19 & 17.03 & 5.54 \\
\hline \multicolumn{10}{|l|}{ Panel B } \\
\hline \multicolumn{3}{|c|}{ RSV model vs. } & \multicolumn{2}{|c|}{ Sign test } & \multicolumn{3}{|c|}{$\begin{array}{c}\text { Wilcoxon signed rank- } \\
\text { test }\end{array}$} & \multicolumn{2}{|c|}{ Vyoung test } \\
\hline \multicolumn{3}{|c|}{ Constant Variance } & \multicolumn{2}{|c|}{$-27.327 *$} & \multicolumn{3}{|c|}{$-19.890 *$} & \multicolumn{2}{|c|}{$-5.160^{*}$} \\
\hline \multicolumn{3}{|c|}{$\operatorname{GARCH}(1,1)$} & \multicolumn{2}{|c|}{$-18.076^{*}$} & \multicolumn{3}{|c|}{$-16.046^{*}$} & \multicolumn{2}{|c|}{$-6.113 *$} \\
\hline \multicolumn{3}{|c|}{$\operatorname{GARCH}(1,1)-\mathrm{L}$} & \multicolumn{2}{|c|}{$-17.853^{*}$} & \multicolumn{3}{|c|}{$-15.479^{*}$} & \multicolumn{2}{|c|}{$-6.614^{*}$} \\
\hline \multicolumn{3}{|c|}{ EGARCH(1,1) } & \multicolumn{2}{|c|}{$-18.121^{*}$} & \multicolumn{3}{|c|}{$-14.921 *$} & \multicolumn{2}{|c|}{$-5.788 *$} \\
\hline \multicolumn{3}{|c|}{$\operatorname{SWARCH}(1,1)$} & \multicolumn{2}{|c|}{$43.861 *$} & \multicolumn{3}{|c|}{$38.635^{*}$} & \multicolumn{2}{|c|}{$-16.838^{*}$} \\
\hline \multicolumn{3}{|c|}{ SSV model } & \multicolumn{2}{|c|}{3.032} & \multicolumn{3}{|c|}{3.956} & \multicolumn{2}{|c|}{$\mathrm{nc}$} \\
\hline
\end{tabular}

\section{Panel A Notes:}

Pars. refers to parameters.

Const. Variance stands for the Constant Variance model with level effect as described below:

$\Delta r_{t}-\left(\hat{a}_{0}+\hat{a}_{1} r_{t-1}\right) \equiv R E S_{t}$ where $R E S_{t}=\sqrt{h r_{t-1}^{2 \alpha}} \varepsilon_{t}, \alpha=0.5$ and $\left(\varepsilon_{t} \mid \Omega_{t-1}\right) \sim N(0,1)$

AIC: Akaike Information Criterion.

SBC: Schwartz Bayesian Criterion.

Adjusted (Adj) $\mathrm{R}^{2}$ : calculated for the regression $R E S_{t}^{2}=a+b h_{t}+u_{t}, u_{t} \sim N(0,1)$ and $\{\mathrm{t}=1, \ldots \ldots, \mathrm{T}\}$ where $R E S_{t}$ are the OLS residuals defined as above, and $h_{t}$ refers to conditional volatility at time t.

Posterior odds ratio: the difference of the SBC of each model and the SBC of the constant variance model.

MSE: Mean squared error defined as $T^{-1} \sum_{t=1}^{T}\left[R E S_{t+1}^{2}-h_{t+1}\right]^{2}$

LL: Logarithmic loss function defined as $T^{-1} \sum_{t=1}^{T}\left[\ln \left(R E S_{t+1}^{2}\right)-\ln \left(h_{t+1}\right)\right]^{2}$.

JB: Jarque-Bera's normality test statistic, where * indicates signific ance at 5\% level.

Panel B Notes:

The test statistic for each of the three tests viz., Sign test, Wilcoxon signed test and Voung test, follows a standard normal distribution. * indicates significance at 5\% level. For the Voung test, nc implies no calculation is possible, as models are nested. 
Table 6. Forecasting Performance

In sample and out-of-sample volatility comparison of alternative models for four different sample periods

\begin{tabular}{|c|c|c|c|c|c|c|c|}
\hline \multirow[t]{3}{*}{ Sample 1} & \multirow{2}{*}{\multicolumn{3}{|c|}{$\begin{array}{l}\text { In-sample (T: 990) } \\
01 / 06 / 60-12 / 31 / 78\end{array}$}} & \multicolumn{4}{|c|}{$\begin{array}{c}\text { Out-of-sample } \\
01 / 01 / 79-06 / 03 / 98\end{array}$} \\
\hline & & & & \multicolumn{2}{|c|}{ fixed sample } & \multicolumn{2}{|c|}{ increasing sample } \\
\hline & MSE & $\mathrm{LL}$ & MAE & MSE & MAE & LL & MAE \\
\hline Const. Variance & 0.0109 & 7.5687 & 0.0266 & 0.0702 & 0.0682 & 7.451 & 0.0007 \\
\hline $\operatorname{EGARCH}(1,1)$ & 0.0104 & 5.4051 & 0.0255 & 0.0707 & 0.0694 & 8.302 & 0.0010 \\
\hline SSV model & 0.0104 & 4.8049 & 0.0255 & 0.0706 & 0.0688 & 6.411 & 0.0007 \\
\hline RSV model & 0.0099 & 3.9309 & 0.0243 & 0.0705 & 0.0685 & 6.346 & 0.0007 \\
\hline \multirow[t]{3}{*}{ Sample 2} & \multirow{2}{*}{\multicolumn{3}{|c|}{$\begin{array}{c}\text { In-sample (T: 1199) } \\
01 / 06 / 60-12 / 31 / 82\end{array}$}} & \multicolumn{4}{|c|}{$\begin{array}{c}\text { Out-of-sample } \\
01 / 01 / 83-06 / 03 / 98 \\
\end{array}$} \\
\hline & & & & \multicolumn{2}{|c|}{ fixed sample } & \multicolumn{2}{|c|}{ increasing sample } \\
\hline & MSE & LL & MAE & MSE & MAE & $\mathrm{LL}$ & MAE \\
\hline Const. Variance & 0.0661 & 8.7843 & 0.0714 & 0.0025 & 0.0132 & 7.321 & 0.00038 \\
\hline $\operatorname{EGARCH}(1,1)$ & 0.0621 & 5.6397 & 0.0679 & 0.0027 & 0.0130 & 8.079 & 0.00045 \\
\hline SSV model & 0.0628 & 5.2738 & 0.0680 & 0.0026 & 0.0126 & 6.037 & 0.00036 \\
\hline RSV model & 0.0616 & 4.2988 & 0.0668 & 0.0026 & 0.0123 & 5.968 & 0.00038 \\
\hline \multirow[t]{3}{*}{ Sample 3} & \multirow{2}{*}{\multicolumn{3}{|c|}{$\begin{array}{c}\text { In-sample (T: 1668) } \\
01 / 06 / 60-12 / 31 / 91\end{array}$}} & \multicolumn{4}{|c|}{$\begin{array}{c}\text { Out-of-sample } \\
01 / 01 / 92-06 / 03 / 98\end{array}$} \\
\hline & & & & \multicolumn{2}{|c|}{ fixed sample } & \multicolumn{2}{|c|}{ increasing sample } \\
\hline & MSE & LL & MAE & MSE & MAE & $\mathrm{LL}$ & MAE \\
\hline Const. Variance & 0.0489 & 8.1319 & 0.0561 & 0.0002 & 0.0067 & 8.127 & 0.00035 \\
\hline $\operatorname{EGARCH}(1,1)$ & 0.0461 & 5.9760 & 0.0538 & 0.0001 & 0.0049 & 8.690 & 0.00039 \\
\hline SSV model & 0.0464 & 5.5601 & 0.0538 & 0.0001 & 0.0047 & 6.898 & 0.00033 \\
\hline RSV model & 0.0458 & 4.9012 & 0.0532 & 0.0001 & 0.0047 & 6.749 & 0.00033 \\
\hline \multirow[t]{3}{*}{ Sample 4} & \multirow{2}{*}{\multicolumn{3}{|c|}{$\begin{array}{c}\text { In-sample (T: 626) } \\
\text { 01/01/76-12/31/87 }\end{array}$}} & \multicolumn{4}{|c|}{$\begin{array}{c}\text { Out-of-sample } \\
01 / 01 / 88-12 / 31 / 89\end{array}$} \\
\hline & & & & \multicolumn{2}{|c|}{ fixed sample } & \multicolumn{2}{|c|}{ increasing sample } \\
\hline & MSE & LL & MAE & MSE & MAE & $\begin{array}{ll}\mathrm{LL} \\
\end{array}$ & MAE \\
\hline Const. Variance & 0.1133 & 7.2008 & 0.1081 & 0.0003 & 0.0119 & 8.045 & 0.00032 \\
\hline EGARCH $(1,1)$ & 0.1090 & 5.9227 & 0.1054 & 0.0005 & 0.0128 & 8.297 & 0.00036 \\
\hline SSV model & 0.1082 & 5.7226 & 0.1051 & 0.0005 & 0.0124 & 6.606 & 0.00029 \\
\hline RSV model & 0.1031 & 4.4926 & 0.1014 & 0.0003 & 0.0115 & 6.282 & 0.00030 \\
\hline
\end{tabular}

- T: refers to the sample size. Const. Variance refers to Constant Variance model. The best model is highlighted in each sample. MSE and LL are defined in Table 5. MAE is the mean absolute error defined as $T^{-1} \sum_{t=1}^{T}\left|R E S_{t+1}^{2}-h_{t+1}\right|$.

- For out-of sample forecasts reported under the column "fixed sample", the estimated coefficients period 1 to $t$ are used to generate one-step-ahead conditional volatility forecasts for each future time period $t+\mathrm{k}$, where $\{\mathrm{k}=1,2,3, \ldots, \mathrm{T}-t\}$ based on the forecasting equations described below: 
Table 6 (continued)

EGARCH(1,1):

$\ln \left(\sigma_{t+s \mid t}^{2}\right)=w_{0}+\left(\beta_{1}\right)^{s-1}\left(\ln \left(\sigma_{t+1 \mid t}^{2}\right)-w_{0}\right)$

where

$w_{0}=\frac{\alpha_{0}}{1-\beta_{1}}$
SSV model:

$\ln \left(\sigma_{t+s \mid t}^{2}\right)=\mu+\left(\phi_{1}\right)^{s-1}\left(\ln \left(\sigma_{t+1 \mid t}^{2}\right)-\mu\right)$

RSV model:

$\ln \left(\sigma_{t+s \mid t}^{2}\right)=\left[\ln \left(\sigma_{t+s \mid t}^{2}\right) \mid \operatorname{pr}\left(s_{t+s}=0 \mid s_{t+s-1}\right)\right] \times \operatorname{pr}\left(s_{t+s}=0 \mid s_{t+s-1}\right)+$ $\left[\ln \left(\sigma_{t+s \mid t}^{2}\right) \mid \operatorname{pr}\left(s_{t+s}=1 \mid s_{t+s-1}\right)\right] \times \operatorname{pr}\left(s_{t+s}=1 \mid s_{t+s-1}\right)$

- For out-of-sample forecasts reported under the column "increasing sample", the successive forecasts are obtained by increasing the sample window, i.e., for time period $t$, the sample size includes observations from 1 to $t$, for the next time period $t+1$, the sample size includes observations from 1 to $t+1$, and so on. We estimate for each time window and forecast for next period. 
Figure 1. Posterior Density Plots for Parameters of the SSV Model
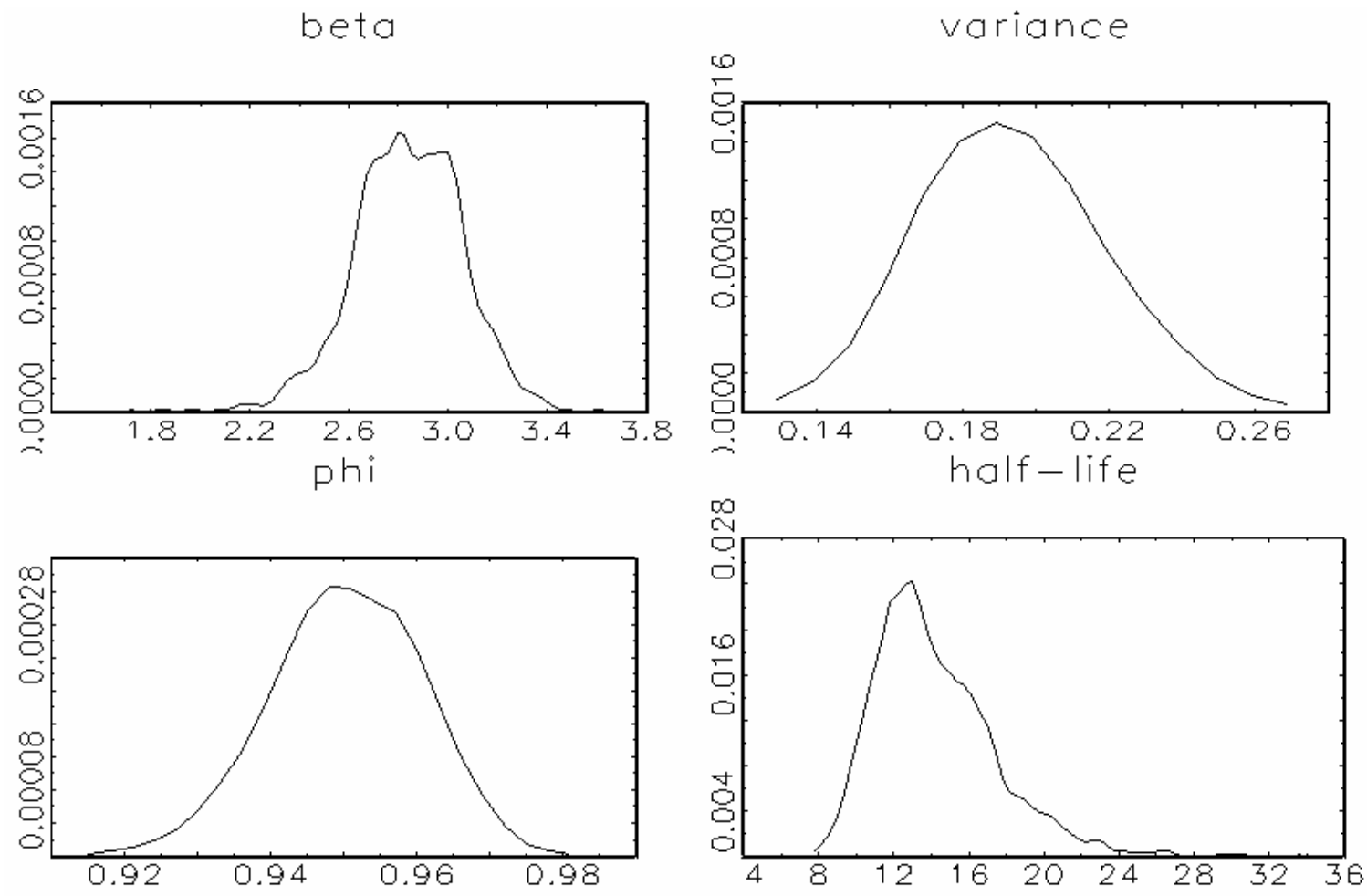

Figure 2. Posterior Density Plots for Parameters of the RSV model
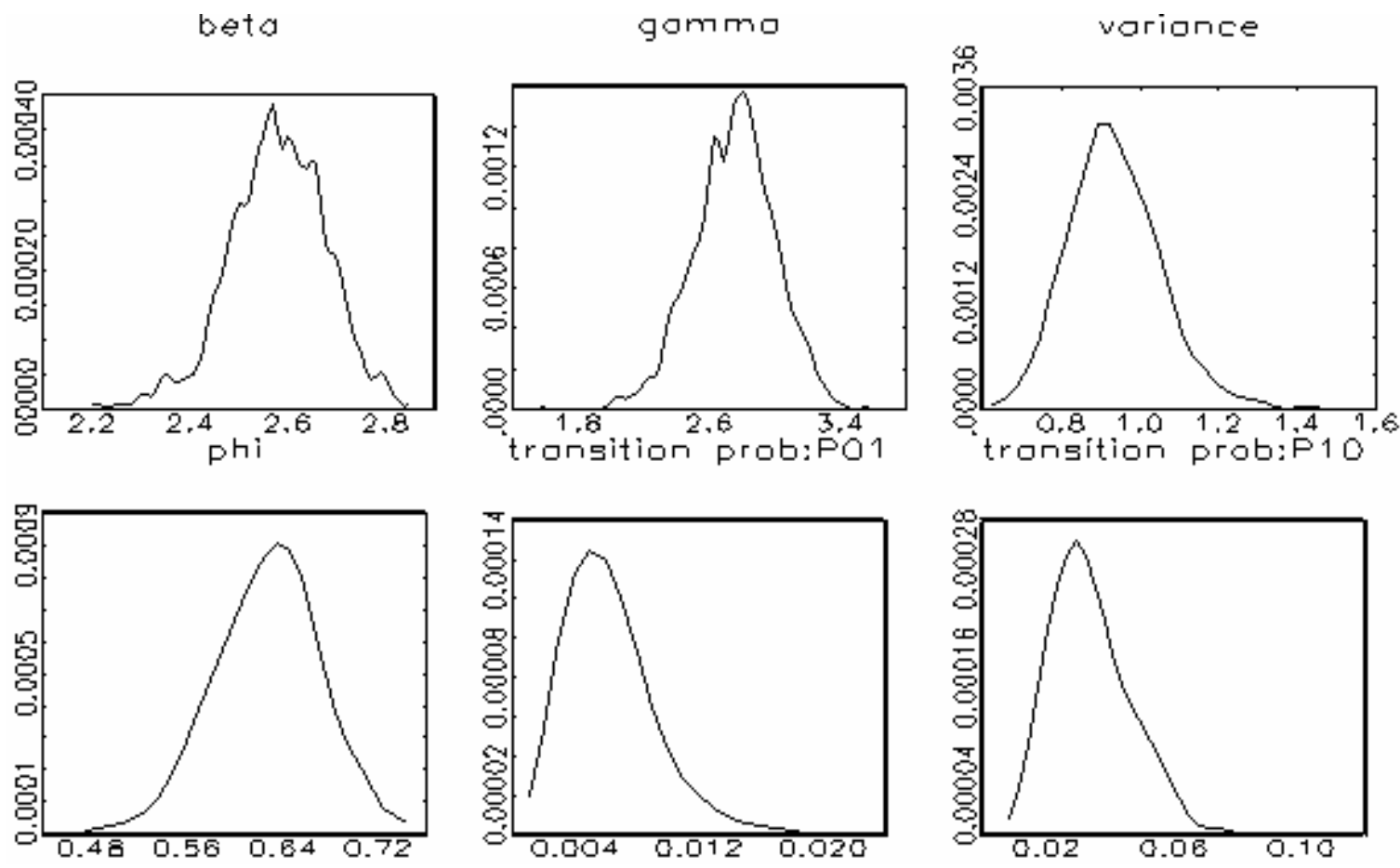
Figure 3. T-Bill Yields and Corresponding Latent Volatility and States (Sample: 01/06/60 to 06/03/98)

U.5. T-Bill yields; $1960-98$
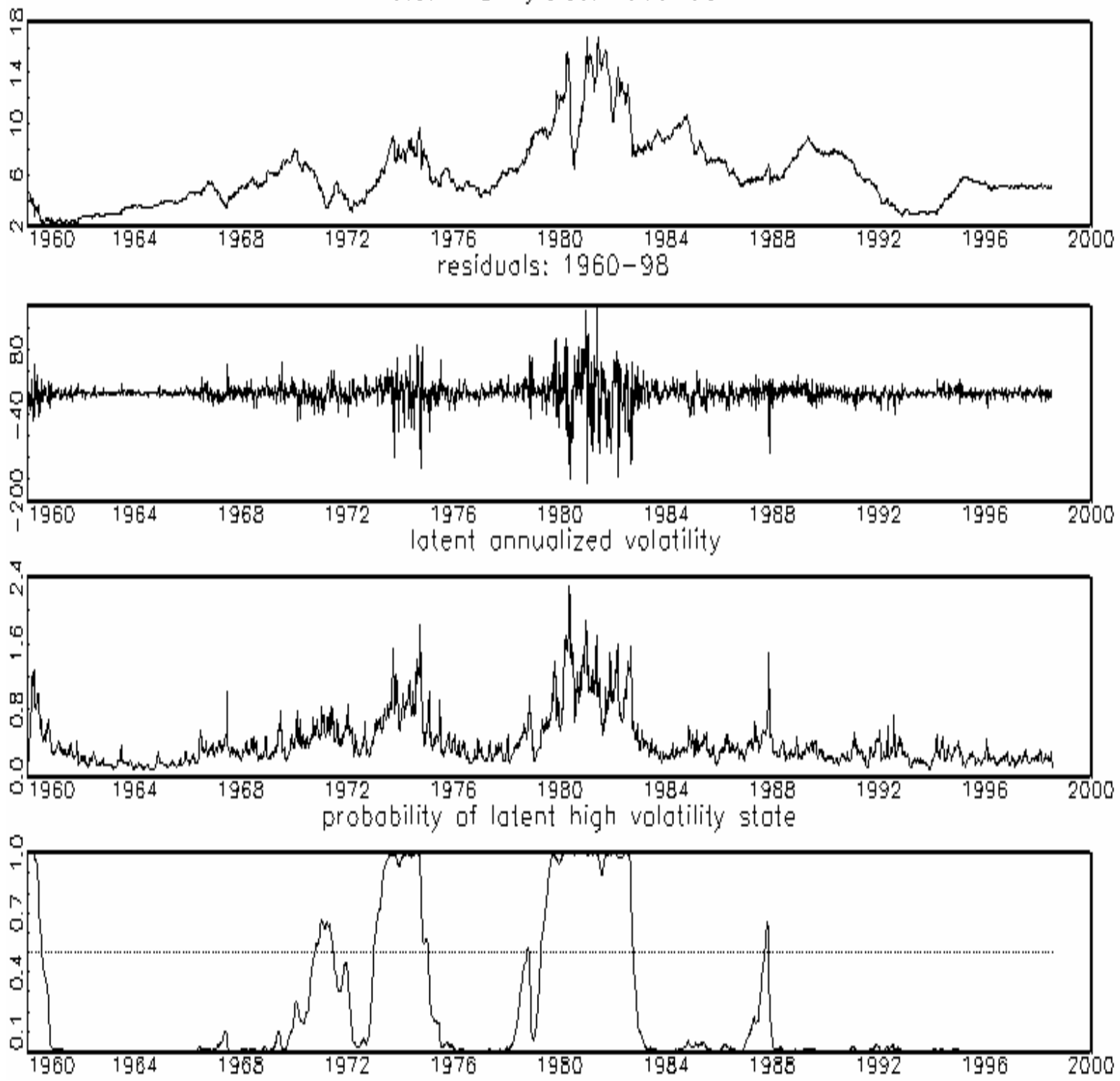
Figure 4. In-sample Latent Conditional Volatility and Probability of High Volatility State from SWARCH(2,1) model (Sample: 01/06/60 to 06/03/98)
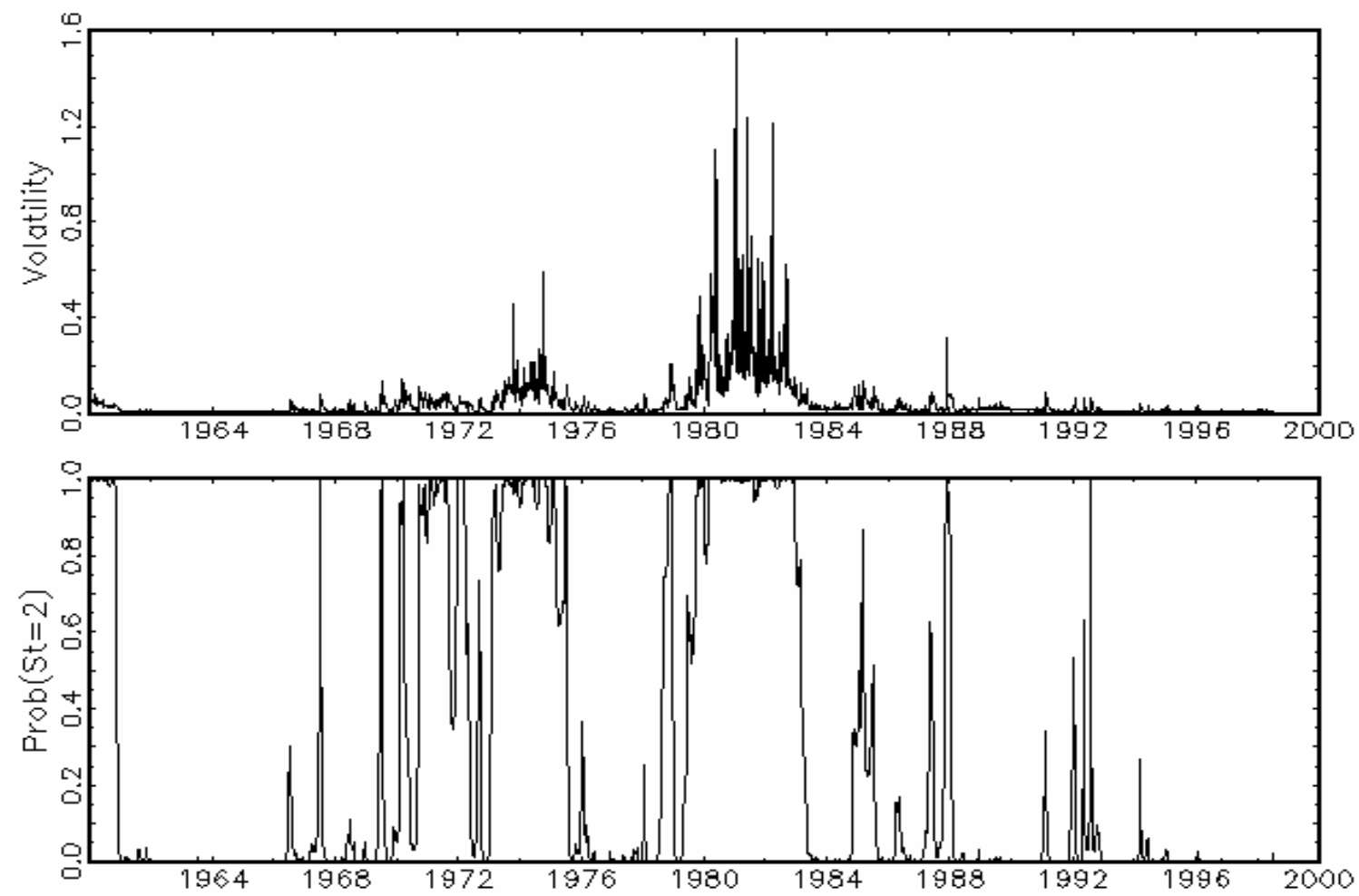